\title{
RENAMO: DE AGENTE DO APARTHEID A ORGANIZAÇÃO POLÍTICA MOÇAMBICANA
}

CAHEN, Michel. "Não somos bandidos": a vida diária de uma guerrilha de direita: a Renamo na época do Acordo de Nkomati (1983-1985). Lisboa: ICS. Imprensa de Ciências Sociais, 2019. 398p.

\section{nascimento de Moçambique} como país foi resultado de uma luta armada, chamada de "luta de libertação nacional”, guerra de uma década desenvolvida pela Frente de Libertação de Moçambique (Frelimo) contra a ocupação colonial portuguesa. A independência conquistada não trouxe paz aos povos moçambicanos. Logo foram estes arrastados para um novo e trágico conflito que, durante 16 anos, destruiu vidas, famílias e infraestrutura, bloqueando as condições de desenvolvimento do país que estava nascendo. ${ }^{1}$

1 Sobre as guerras em Moçambique, ver Arcénio Francisco Cuco e Pascoal Muibo, "A violência como mito fundador de Moçambique”, Mosaico, v. 11, n. 17 (2019), pp. 141-163. Ver também
Após a conquista da independência foi criada uma organização militar, a Resistência Nacional de Moçambique (RNM ou Renamo), cujo objetivo era confrontar o novo governo promovendo sabotagens, atentados e pequenos ataques até que, com o desenrolar da cena política moçambicana, essa organização foi se transformando, ampliando sua dimensão política e passando a, paulatinamente, polarizar e disputar os destinos do país. A Renamo tornou-se um dos protagonistas da luta institucional em Moçambique, e assim segue até os dias atuais.

Felizardo Gabriel Masseko, “A Guerra dos 16 anos em Moçambique: causas nacionais e internacionais?”, Revista Nordestina de História do Brasil, v. 2, n. 3 (2019), pp. 120-136. 
O estudo deste período da história de Moçambique é extremamente delicado porque se trata de um processo em aberto, cujos atores institucionais, bem como muitos dos seus integrantes, das cúpulas e das bases, estão vivos, ou estavam até recentemente, presentes e atuantes. Assim, toda e qualquer abordagem, necessariamente, tem implicações políticas imediatas nas disputas em curso, o que condiciona o trabalho do pesquisador. O que foi a guerra entre o governo moçambicano e a Renamo? As correntes interpretativas se dividem entre designações como "guerra imperialista" contra um Estado socialista; "guerra de sabotagem”; ação de "bandidos armados" contra o povo. Em outra perspectiva, foi uma "guerra civil" ou, mais tarde, uma "guerra pela democracia”.

Tais definições expressam interesses, são pontos de vistas dos atores em conflito. Assim, luta armada, disputa política e o debate historiográfico sobre tais conflitos apresentam uma conexão muito direta, quebrando qualquer ilusão de distanciamento regulamentar. São os riscos de se escrever História do tempo presente, riscos que acadêmicos moçambicanos tentam contornar ao designar esse processo como a "Guerra dos 16 anos" ou "Guerra entre irmãos”. Trata-se de fugir da polarização e estimular a luta pela paz e a reconciliação nacional, processo difícil, tenso e incerto cujos marcos podem ser identificados na aprovação de uma nova constituição, em 1990, no Acordo Geral de Paz, assinado em 1992, e na realização das primeiras eleições gerais multipartidárias, em 1994, sem que tudo isso tenha significado, até o presente, uma "paz definitiva, duradoura”.

Michel Cahen mergulha nesse cenário complexo com uma obra provocante, que busca analisar a transformação da Renamo, de uma organização puramente militar para um estágio no qual uma dimensão política teria passado a ser relevante, ainda que secundária diante de outros protagonistas políticos. Investigador de larga experiência, desde os anos de 1980 Cahen estuda e publica trabalhos sobre guerra, economia e a vida política de Moçambique, ${ }^{2}$

2 Um resumo da significativa produção de Michel Cahen pode ser encontrado numa consulta ao Memória d'África $e$ d'Oriente 
partindo de sólida pesquisa em arquivos e também de imersão direta, a exemplo dos dois meses em que conviveu com o comandante da Renamo, Afonso Dhlakama, durante a campanha eleitoral de $1994{ }^{3}$

Em Não somos bandidos Cahen desafia o pensamento hegemônico que, segundo ele, seria francamente favorável à Frelimo ao negar a dimensão política das ações da Renamo, classificando-as como expressão dos interesses dos regimes racistas da África do Sul e da Rodésia, ou como mera ação de bandidos armados. Sua obra busca estabelecer outra visão ao descrever a "Resistência Nacional de Moçambique (Renamo) - grupo armado que combateu o regime da Frente de Libertação de Moçambique (Frelimo) de 1977 até 1992 e hoje é o maior partido de oposição -, tal como aparece nos Cadernos da Gorongosa” (p. 21).

3 Em entrevista concedida a Adelino Gomes, em 2002, por ocasião do lançamento do livro Les Bandits - Un historien au Mozambique, 1994, Cahen discute a experiência de imersão no cotidiano da Renamo. Ver "Historiador francês quebra 'tabu metodológico' e acompanha ‘bandidos’ da Renamo”, Público, Lisboa, 12 out. 2002 ש.
A serra da Gorongosa é uma região de Moçambique onde a Renamo está fortemente implantada e que, nos tempos da guerra, concentrava vários grupos de ação, inclusive o quartel-general da organização, numa localidade chamada Casa Banana. Cahen descreve a ocupação deste QG pelas forças governamentais, em agosto de 1985, e a perda de material bélico pesado que não foi possível evacuar. Neste ataque, a oposição armada perdeu também uma "uma parte de seus arquivos, que os serviços de segurança do governo moçambicano se apressaram a estudar” (p.22). São esses documentos que ficaram conhecidos como Cadernos da Gorongosa. Destaca-se que o governo moçambicano publicou excertos desta documentação que comprovavam a presença da África do Sul na vida da Renamo. O comandante desta organização, Afonso Dhlakama, alegou serem os documentos falsos e Cahen disse que, "De certa maneira, ele tinha razão: como o título mesmo indicava, eram 'extratos', mas extratos cuidadosamente escolhidos com o fim único de comprovar a presença sul-africana” (p. 23). 
Apesar de contestar a publicação dos excertos selecionados, Cahen afirma que os Cadernos são documentos verdadeiros, pois possuem tantos detalhes que não poderiam ser forjados. Não se sabe quantos Cadernos foram apreendidos pelo governo e nem onde todo esse material foi parar. $\mathrm{O}$ fato é que não estão em nenhuma instituição, biblioteca, ou arquivo em Moçambique. Os cadernos são compostos por "milhares de mensagens de rádio, decifradas, entre os grupos locais da Renamo e o respetivo Estado-Maior-General” (p.25). Em outras palavras, correspondência interna que tratava da vida cotidiana da organização. $\mathrm{O}$ autor teve acesso parcial à essa documentação inédita e valiosíssima, mas, surpreendentemente, afirma não poder revelar as razões de tal privilégio.

Por razões que não podem ser reveladas, tive a possibilidade de consultar e estudar alguns dos Cadernos, que foram "extraviados" do lote por quem, ao serviço de um governo estrangeiro (não o meu), queria saber do que se tratava. Com certeza, são só uma parte, mas que é suficiente para comprovar a extraordinária riqueza documental do todo, caso venha a aparecer um dia (pp. 26-27).
Cahen organizou, numerou e classificou a documentação que recebeu, conforme descreve detalhadamente. ${ }^{4}$ Analisou 3.401 mensagens, que permitiram mapear a estrutura, o funcionamento, as relações internas, estratégias de atuação da Renamo. Adverte o leitor para as dificuldades de trabalhar com essa fonte, citando como exemplo os trechos ilegíveis, o problema da localização espacial de alguns dos eventos citados e a nem sempre possível identificação dos autores das mensagens. Apesar de tais limitações, o resultado deste esforço é um conjunto de informações significativas sobre a implantação, estrutura, hierarquia, as regiões militares, os combates, o material bélico, as relações com a população, o perfil dos combatentes da Renamo, entre os anos de 1983 e 1985. Um trabalho inédito, pois, pela primeira vez, esta organização é estudada a partir de uma documentação interna, a Renamo vista pela Renamo.

Refletindo criticamente sobra a documentação, Cahen questiona se

4 Ver a nota 15, p. 26. Vale destacar que as notas são um capítulo especial, pela riqueza de detalhes, fundamentação bibliográfica e explicitação metodológica sobre os problemas e escolhas do autor no tratamento da documentação. 
o material a que teve acesso não é, assim como os extratos publicados pelo governo, também uma seleção igualmente calculada. Neste caso, com objetivo oposto, de secundarizar ou apagar a presença da África do Sul no cotidiano da Renamo. Considera que isso é improvável, entre outros motivos, pelo fato destes "cadernos nunca terem sido usados para comprovar a tese contrária, a saber, que a Renamo teria pouca ligação com a África do Sul” (p. 30).

O conjunto dos Cadernos foi apropriado por um governo estrangeiro? Um agente deste governo extraviou parte da documentação e a repassou ao nosso autor? Fez isso por conta própria ou se trata de uma ação deliberada, calculada pelo mesmo "governo"? São questões relevantes para pensarmos sobre as intenções de quem fez a seleção do conjunto que chegou às mãos de Cahen. Infelizmente, a obra não apresenta respostas para tais questões e o leitor é obrigado a confiar e aceitar a conclusão de que o extravio feito tinha o objetivo de meramente saber o que era a Renamo. Cahen reconhece que "Escrever um livro com base numa documentação arquivística a que ninguém mais podia ter acesso foi metodologicamente e eticamente problemático" (p.30). Ainda assim, correu o risco e seguiu em frente.

Entregou uma obra cujo objetivo é pensar a Renamo como uma organização que era mais do que um agrupamento militar submetido a um poder externo. Para o autor, tratava-se de uma organização com enraizamento interno a Moçambique e capaz de estabelecer objetivos estratégicos e políticos, ainda que a dimensão militar fosse preponderante. O período estudado é particularmente interessante para essa abordagem, pois dois eventos modificaram o cenário da guerra em Moçambique, colocando para a Renamo o dilema entre uma derrota militar e um possível desaparecimento, ou a sua transformação e busca de enraizamento para sobreviver por conta própria politicamente.

Os marcos deste cenário foram a queda do regime racista de Ian Smith, com o nascimento do Zimbábue (antiga Rodésia) e o pacto assinado entre o governo de Moçambique e o da África do Sul, conhecido como Acordo de Nkomati. Os dois eventos atingiam diretamente a Renamo, na sua origem, constituição e sustentação. Segundo 
Malyn Newitt, depois da independência de Moçambique,

Aqueles que estavam mais envolvidos na oposição à Frelimo fugiram para o estrangeiro, levando consigo uma determinação para a sabotagem do novo regime. O governo de Ian Smith foi o primeiro a dar algum apoio aos Moçambicanos dissidentes. Jorge Jardim e o seu agente Orlando Cristina terão fugido com alguns processos da DGS e ajudado os rodesianos a fundar a RENAMO, recrutando elementos de unidades militares e paramilitares negras que haviam combatido para os portugueses. Sob o controle firme da organização de segurança rodesiana, a Renamo desenvolveu-se primeiro como uma unidade militar e não como um movimento político. ${ }^{5}$

A Renamo nasceu como uma unidade de mercenários a serviço do regime rodesiano que visava impedir que a experiência de Moçambique, governada pela maioria negra, chegasse ao seu próprio território. Não seria outro o motivo da África do Sul, mais um país com governo racista, ter assumido o lugar de Smith logo após a conquista do poder pela

5 Malyn Newitt, História de Moçambique, Lisboa: Publicações Europa-América, 1995, p. 482. A DGS era a Direção Geral de Segurança, órgão de repressão do governo colonialista português. maioria negra na então chamada Rodésia. A Renamo passou a receber apoio, material e treinamento do regime do Apartheid, ao se transferir para a África do Sul, de onde partia para ataques em Moçambique. Ainda que as secundarize, Cahen confirma tais conexões em diversas passagens de sua obra, por exemplo, quando afirma que "A continuação do apoio sul-africano, em escala mais reduzida, porém preciosa para a Renamo, não me parece possível de ser contestada" (p. 24). Indo além, informa que "Parte da direção da Renamo e das infraestruturas, entretanto, ficou na África do Sul, nomeadamente no 'estado-maior da retaguarda', em Phalaborwa, destinado principalmente à logística e à escuta” (p. 35). E, para que não restem dúvidas, "nessas regiões em expansão eram comuns queixas pela falta de material, ainda que naquela altura o Acordo de Nkomati ainda não tivesse sido celebrado e, portanto, a África do Sul reabastecia a Renamo quase que oficialmente” (p.53).

$\mathrm{O}$ engajamento dos regimes racistas da África do Sul e da Rodésia na disputa sobre os destinos de Moçambique, criando e sustentando a Renamo, era parte da estratégia de 
inviabilizar um possível êxito das experiências de autogoverno negro, o que teria reflexos subjetivos e objetivos em toda a região. As ações de sabotagem contra o governo da Frelimo foi parte desta guerra de baixa intensidade que buscava manter o desgaste provocado pelo estado de conflito permanente. Não se tratava de vencer, mas de impedir o outro de governar.

O Acordo de Nkomati, celebrado com a África do Sul em 16 de março de 1984, foi um movimento ousado e polêmico do governo de Samora Machel visando quebrar essa lógica da guerra permanente. O pacto implicava no compromisso dos dois governos em cortar o apoio aos movimentos insurgentes no território vizinho. Moçambique deixaria de apoiar o Congresso Nacional Africano e, em troca, o Apartheid deixaria de apoiar a Renamo. Tratava-se de uma estratégia mais ampla que incluía mudanças na política externa, aproximação com o Ocidente, busca de capitais privados e reestruturação econômica interna. Apesar do acordo, o Apartheid continuou apoiando a Renamo, mas em escala mais reduzida.

Tal foi o cenário que levou a Renamo a se transformar, buscando criar raízes, bases sociais e capacidade de desenvolver operações militares em todo o território moçambicano para seguir a guerra por meios próprios. Cahen, nos dois capítulos iniciais, demonstra a relevância do período entre os anos de 1983 a 1985 para esta transição. Criada e sustentada pelos regimes racistas para promover a sabotagem e a desestabilização em Moçambique, concluiu o autor que "a estrutura interna da Renamo em fins de 1984 estava madura para uma guerra civil à escala de todo o país” (p. 50).

$\mathrm{O}$ autor descreve a estratégia da Renamo de avançar para o Norte, visando instalar capacidade de ação militar em todo território antes que o governo concluísse as negociações de paz com a África do Sul. A atividade prioritária desta expansão era atacar as aldeias comunais para desorganizar a produção e, ao mesmo tempo, explorar a insatisfação de camponeses aldeados involuntariamente pelo governo. Segundo Cahen, a "modernização autoritária” promovida pelo governo, na estruturação política e econômica, abria brechas para crises e tensões que o grupo guerrilheiro demonstrou capacidade de usar, apresentando as políticas da Frelimo 
como responsáveis pela pobreza que não seria decorrente de uma herança colonial ou mesmo consequência da guerra em curso.

Havia uma batalha pela conquista das populações, indicativo de que a guerrilha também esboçava objetivos políticos. A busca pelo controle da população, tanto a que estava em seus domínios quanto com a que estava nas zonas do “inimigo", era estratégica. Ter inserção entre os civis significava proteção para suas bases de ação, apoio em tarefas paramilitares, de transporte e carregamento. A disputa era pensada como uma guerra entre duas populações e não apenas dois exércitos. Cahen apresenta uma série de evidências extraídas da documentação para mostrar que os limites entre "elementos da população" e os "elementos do inimigo" não eram nítidos, o que levava a execuções não só de combatentes (pp. 141-148).

Os Cadernos examinados por Cahen revelam aspectos mais estritamente militares, sobre recrutamentos, raptos, deserções, punições, inclusive execuções, treinamento, hierarquia, natureza dos combates, guerra de guerrilha e semiconvencional. São evidências que permitem traçar o perfil de uma organização disciplinada e ultracentralizada, na qual ações das mais cotidianas dependiam de ordens superiores, do Estado-Maior ou, frequentemente, do próprio Afonso Dhlakama, comandante supremo da Renamo que a tudo controlava.

A exaustiva coleta de dados pela Renamo indica a profunda cultura burocrática que a caracterizava, resultando na troca sistemática de mensagens, desde as Unidades Operacionais até o Estado-Maior. Assim, Cahen pôde captar, e apresentar ao longo dos dezessete capítulos da obra, além da dimensão estritamente militar, diversos traços do cotidiano nas áreas controladas, desde a estruturação da produção, o controle dos alimentos, o combate ao mercado paralelo, a centralização dos bens, até aspectos sociais, como o funcionamento de escolas e cuidados com a saúde, relações de gênero entre os militares e destes com os civis, casamentos forçados, raptos e violações. Cahen relativiza certas atitudes chamando atenção para que as mesmas não seriam exclusividade da Renamo. Um tema para pensar, já que os Cadernos são constituídos por mensagens da própria guerrilha. 
Um capítulo à parte, assim como as notas, são os quadros e listas elaborados pelo autor, que retratam um panorama das regiões, setores, bases, zonas e unidades operacionais, uma geografia detalhada do "dispositivo militar regional” da Renamo entre 1984 e 1985, que o leitor pode estudar ao longo da obra, mas, especialmente, no seu anexo. A descrição detalhada da estrutura militar permite concluir que não se tratava de um grupo de "mercenários", de "bandidos armados" ou de simples "senhores da guerra”, mas, ao contrário, seria um exército pronto para a guerrilha e a guerra semiconvencional. Cahen destaca a singularidade da organização neste período em que, se ainda não era um partido político, também não era um grupo de criminosos.

O trabalho de Cahen é uma contribuição magistral para o conhecimento da história de Moçambique contemporânea pelo ineditismo de estudar um dos protagonistas a partir de documentação interna. O leitor perceberá o rigor metodológico e o cuidado ético do autor, que alerta para os limites da fonte sem deixar de enfrentá-los e, ao mesmo tempo, sem nunca fugir da fonte, pois sempre são os Cadernos que falam, que sugerem, que permitem perceber e dizer. Não deixa de analisar, problematizar e desafiar o conhecimento estabelecido e assim abre espaço para a reflexão e a crítica.

O autor critica sistematicamente a literatura histórica sobre as guerras em Moçambique, alegando que a mesma é amplamente favorável à Frelimo, que teria o controle das fontes e a simpatia dos estudiosos. Argumenta que os estudos sobre a Renamo são produzidos com base em documentação gerada pelo "mundo social da Frelimo", o partido, o Estado, os acadêmicos, moçambicanos e estrangeiros, que operam sem o devido distanciamento. Cabe perguntar se Cahen não inverte o sinal tentando construir uma literatura favorável à Renamo ou se conseguiu atingir o devido distanciamento. Não seria o caso de dizer que está produzindo a partir de um "mundo social da Renamo"?

Secundarizar a origem e as ligações da guerrilha de direita com a Rodésia e a África do Sul, regimes racistas quase nunca nomeados enquanto tal, não seria excessiva generosidade quando o próprio autor fornece numerosas indicações 
sobre essas conexões? A estratégia de construir uma base social em Moçambique e expandir a capacidade de ação militar para todo o território antes do Acordo de Nkomati, muito bem descrita, não é mais uma pista sobre a ação coordenada da Renamo com o Apartheid?

Segundo Cahen, a implantação da Renamo em Moçambique foi fruto dos erros políticos da Frelimo, o que parece razoável, mas até que ponto as escolhas da Frelimo não foram marcadas pela imposição da guerra de desestabilização, do cerco implacável que os regimes racistas, apoiados pelo Ocidente, desenvolveram contra os governos de maioria negra que então se declaravam anticapitalistas, a exemplo de Angola e Moçambique?

Apesar das advertências iniciais do autor, a impressão que fica é que ele devota demasiada confiança na fonte, sem dúvida rica e até preciosa, mas que é, eu insisto, uma seleção, extratos como aqueles publicados pelo governo moçambicano e que Cahen critica por ser parcial e voltado para um objetivo bem específico. O leitor não tem noção nenhuma sobre qual foi o serviço de inteligência, qual foi o governo que se apropriou destes
Cadernos da Gorongosa. Igualmente, nada se sabe acerca do agente que desviou, extraviou uma parte desta documentação e, generosamente, a repassou ao historiador, que valoriza as mensagens em função de sua natureza de registro interno, corriqueiro e sistemático das atividades de comando da Renamo. Sem dúvida isso é valioso, mas não se deve esquecer que o material analisado não foi o conjunto da documentação e sim uma seleção, que não foi feita pelo investigador, abrangendo um período bem específico. Os Cadernos "não eram para inglês ver", mas quanto à seleção dos trechos, já não se pode ter tanta certeza.

Os extratos dos Cadernos da Gorongosa examinados por Michel Cahen permitem traçar um panorama do período entre 1983 e 1985, marcado por transições significativas para todo o cone sul da África, no qual a "RNM virou Renamo”. Permitem também retratar as sabotagens protagonizadas por uma organização com capacidade de desenvolver guerra de guerrilha em todo território de Moçambique, evidenciando a dimensão política de suas ações, que lhe permitiu dividir com a Frelimo o protagonismo da 
vida política e institucional do país, como já dito, até aos dias atuais, alternando períodos de paz tensa e de conflitos armados.

A guerra desestruturou relações sociais e deixou feridas difíceis de curar - massacres, assassinatos, roubos, execuções, violações e todo tipo de atrocidades foram cometidas de parte a parte. Apesar disso, Moçambique segue no extraordinário esforço para construir pontes, perdoar, virar a página e consolidar “uma paz duradoura e efetiva", conforme as negociações diretas entre o presidente da república, Felipe Nyusi, e o líder da Renamo, Afonso Dhlakama, realizadas na Serra da Gorongosa. ${ }^{6}$ A obra de Cahen, para além da aula sobre como deve ser o trabalho do historiador, ao colocar a visão da Renamo sobre sua própria história, pode ser vista também como uma contribuição ao esforço de uma reconciliação tão desejada pelos moçambicanos.

\section{Juvenal de Carvalho Conceição (D)}

Universidade Federal do Recôncavo da Bahia

doi: 10.9771/aa.v0i62.42889

6 Juvenal de Carvalho Conceição, "Imprensa, representações da África e hegemonia ocidental” in Mário Jorge Caetano Brito dos Santos e Arcénio Francisco Cuco (orgs.), Disputas identitárias, imprensa e democracia: olhares sobre os processos de construção do "Nós" (Nampula, Moçambique: CIEDIMA/ Universidade Rovuma, 2019), pp. 35-52. 